\title{
Assessment of human-induced vibrations of a cable-stayed footbridge
}

\author{
Izabela Drygała ${ }^{1, *}$, Joanna M. Dulinska ${ }^{1}$, Marek Wazowski ${ }^{2}$ \\ ${ }^{1}$ Cracow University of Technology, Warszawska 24, 31-155 Krakow, Poland \\ ${ }^{2}$ Aspekt Laboratorium Sp. z o.o., Chopina 96, 43-600 Jaworzno
}

\begin{abstract}
The primary purpose of this research is the evaluation of humaninduced vibrations of a cable-stayed footbridge. The cable-stayed pedestrian bridge with total length of the span equal to $46.90 \mathrm{~m}$ located in Czestochowa (Southern Poland) was chosen as a case study. The footbridge consists of two spans $(21.10 \mathrm{~m}$ and $25.80 \mathrm{~m})$. A three-dimensional (3D) finite element (FE) model of the footbridge was prepared with the ABAQUS software program. The dynamic properties of the structure, i.e. its natural frequencies, modes shapes and damping ratios, were estimated on the basis of the in situ tests results as well as numerical analysis. For the validation of the modal models the modal assurance criterion (MAC) theory was applied. In the next stage of the investigation the dynamic response of the structure to humaninduced loading was evaluated. Finally, the vibration comfort criteria for the footbridge were checked.
\end{abstract}

\section{Introduction}

Although, static loading as well as serviceability requirements are important considerations, dynamic problems are much more challenging in the designing of pedestrian bridges. It must be pointed out, that the application of unconventional materials, technologies and optimisation methods has an influence on the dynamic behaviour of pedestrian bridges [1-5]. Because of their properties, e.g. their low levels of stiffness, it has been observed that the large number of contemporary footbridges have their first natural frequency within the range that is typical for dynamic loading generated by people during walking or running [3]. Taking into consideration the primary destination of the pedestrian bridges, the risk of the resonance phenomenon occurring has to be discussed for this type of structure [3]. For this reason, the dynamic performance of pedestrian bridges is one of the most important issues which the designers of the footbridges have to consider.

In this paper the dynamic analysis of the cable-stayed pedestrian bridge, which was erected in Czestochowa (Southern Poland), is presented. Firstly, the results of modal properties investigation were delivered. Then, the assessment of human-induced vibrations of the structure were discussed. For both stages of the research, the numerical as well as experimental analysis were conducted since this approach made possible to verify results.

\footnotetext{
* Corresponding author: idrygala@pk.edu.pl
} 


\section{Structural layout and FE model of the footbridge}

For the study purposes, an existing doubly span cable-stayed footbridge was chosen as a case study [6]. The structure was erected in Czestochowa (Southern Poland) and consists of two spans $(21.10 \mathrm{~m}$ and $25.80 \mathrm{~m})$. The primary purpose of the footbridge is to carry pedestrians and cyclists over the national expressway DK-1. The total theoretical length of structure is equal to $46.90 \mathrm{~m}$. The structure was designed according to technical requirements demanded for footbridges [3]. In Fig. 1, the overall structural layout of the footbridge as well as the location of control points with accelerometers (points: A1, A2, A3 and A4) are presented.

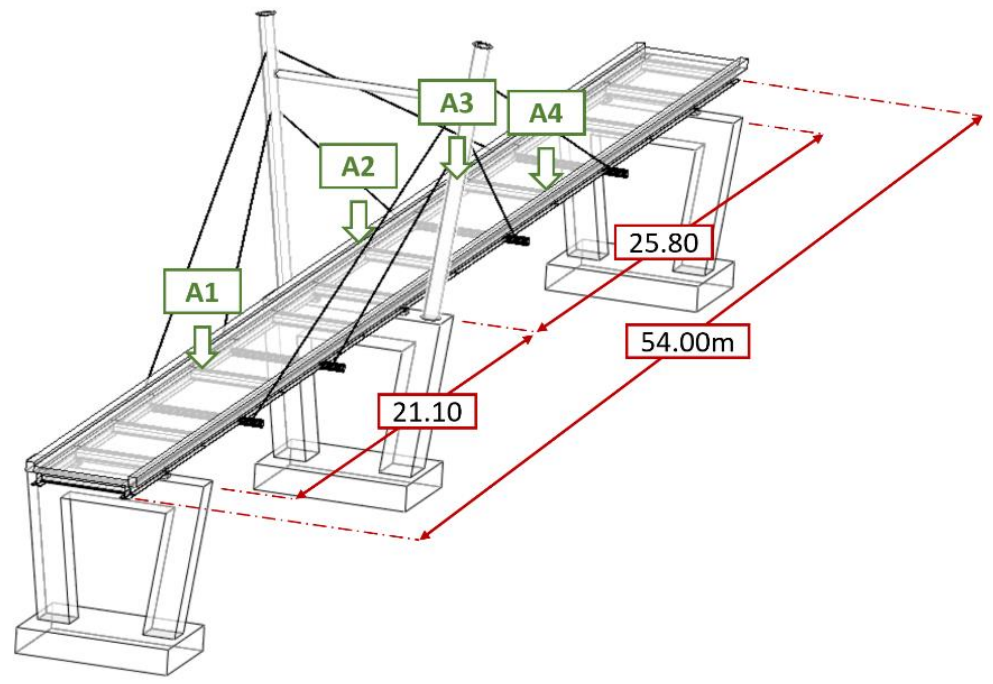

Fig. 1. Overall structural layout of the investigated footbridge.

The footbridge is supported by three reinforced concrete pillars (see Fig. 1) with a cross section of $1.0 \times 1.2 \mathrm{~m}$ and $0.8 \times 0.8 \mathrm{~m}$ for the middle and the extreme pillars. The structure is suspended from a pylon $13.20 \mathrm{~m}$ high situated above the middle support (four ASDO M42 trusses on both sides of the deck). The trusses are hinged to the pylon and to the deck. The pylon was realized as steel pipes of a diameter $457 \mathrm{~mm}$ with $50 \mathrm{~mm}$ wall thickness with concrete inside. The footbridge deck is composite steel-concrete slab. The main girders are integrated with a concrete deck by steel bolts. The thickness of the deck varies from 0.17 to $0.20 \mathrm{~m}$. The primary structural system of the footbridge consists of steel girders (I-section HEB 400) located at a distance of $2.8 \mathrm{~m}$ and connected by crossbars (I-section HEA 300). The 3D FE model of the footbridge was prepared with ABAQUS/Standard software program. Total number of degrees of freedom in FE model is equal to 32599 and the total number of finite elements is equal to 22598 . For numerical analysis, the modulus of elasticity of steel parts of the structure was assumed as $210 \mathrm{GPa}$. The Poisson's ratio was assumed as 0.29 . The material data of concrete were assumed: the modulus of elasticity - $35 \mathrm{GPa}$, the Poisson's ratio -0.17 and the mass density $-2500 \mathrm{~kg} / \mathrm{m}^{3}$. The structure is equipped with elastomeric bearings which are the linking elements between the girders and the piers. In the work the parameters of the Mooney-Rivlin model (assumed as $C_{10}=0.292 \mathrm{MPa}$ and $C_{01}=0.177 \mathrm{MPa}$ ) were replaced with the equivalent elasticity modulus $(2.814 \mathrm{MPa})$. Such simplification is used in calculations of bridges with elastomeric bearings [6]. The Poisson's ratio of elastomeric material was taken as 0.49 . As a result of the numerical modal analysis, the first three natural frequencies and mode shapes of the structure were obtained. 


\section{Modal properties of the footbridge}

The evaluation of modal properties of the footbridge was the first stage of the investigation. During the in situ tests, the experiment with impulsive excitation was made. The impulsive excitation was realized by jump of group of six people. In Fig. 2a, the time history of accelerations in vertical direction for every control point, i.e. A1, A2, A3 and A4, is presented. In Fig. 2b, amplitude-frequency spectra calculated for all signals are summarized. The dynamic characteristics of the structure were also extracted by a linear perturbation numerical procedure provided by the ABAQUS/Standard software program [7]. The estimated values of natural frequencies of the footbridge as well as the comparison of the numerical and experimental results are presented in Table 1. As a criterion of the compatibility of the results, the modal assurance criterion (MAC) theory was chosen [8]. The values of the MAC index are also presented in Table 1. In Fig. 3, the mode shapes of vibrations of the investigated footbridge are presented. Taking into consideration the MAC values as well as natural frequencies which were obtained, a good agreement between the numerical and experimental results was observed (see Tab 1).
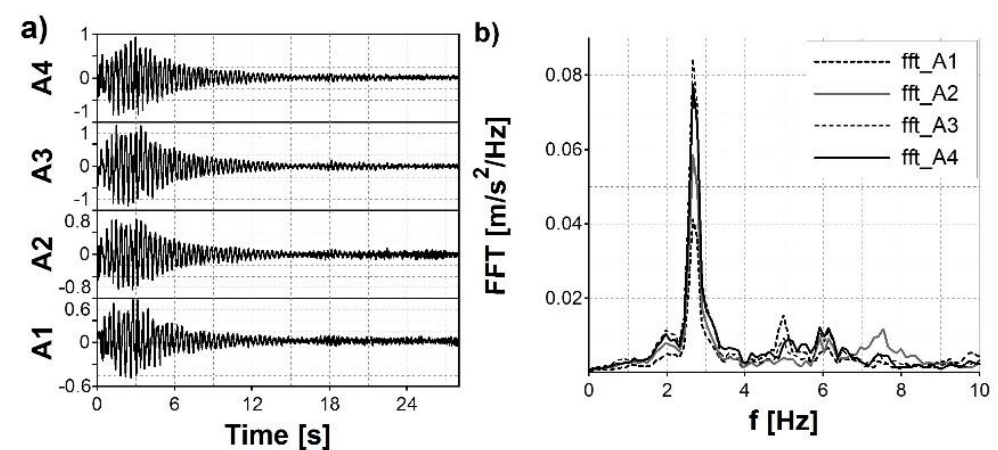

Fig. 2. The impulsive excitation: (a) time history of accelerations and (b) frequency spectrums

Table 1. Dynamic characteristics of the footbridge [6].

\begin{tabular}{|c|c|c|c|c|c|}
\hline \multirow{2}{*}{$\begin{array}{c}\text { Vibration } \\
\text { mode }\end{array}$} & \multicolumn{2}{|c|}{ Frequency $[\mathrm{Hz}]$} & \multirow{2}{*}{$\begin{array}{c}\text { Differences } \\
{[\boldsymbol{\%}]}\end{array}$} & $\begin{array}{c}\text { MAC } \\
{[-]}\end{array}$ & $\begin{array}{c}\text { Logarithmic } \\
\text { decrement } \boldsymbol{\delta}[-]\end{array}$ \\
\cline { 2 - 3 } & $\boldsymbol{F}_{\boldsymbol{F E}}$ & $\boldsymbol{F}_{\boldsymbol{E X P}}$ & 1.81 & 0.99 & 0.086 \\
\hline 1 & 2.71 & 2.76 & 5.70 & 0.86 & 0.060 \\
\hline 2 & 5.19 & 4.91 & 3.95 & 0.95 & 0.056 \\
\hline 3 & 6.32 & 6.08 & &
\end{tabular}

a)

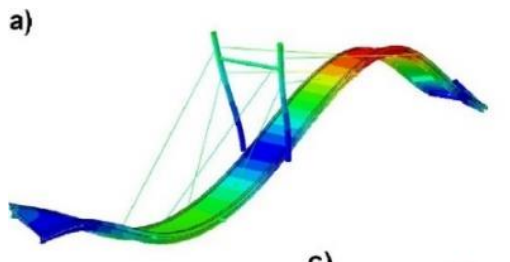

c)
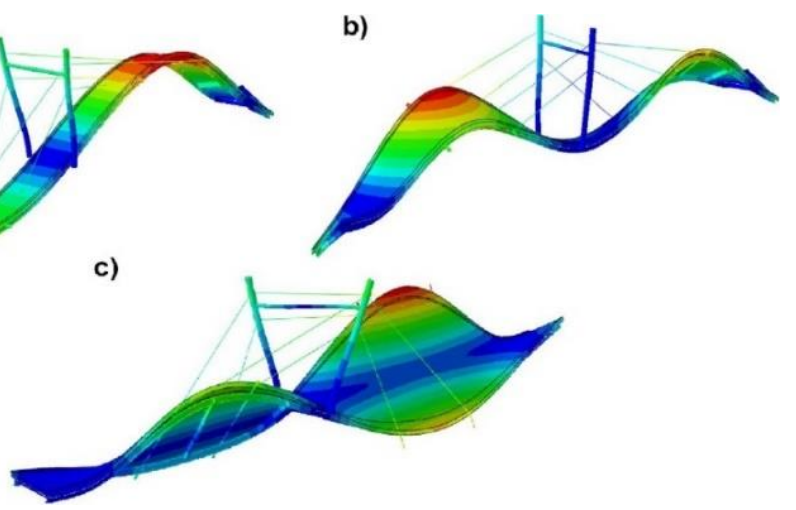

Fig. 3. The mode shapes of vibrations: (a) $\mathrm{f}_{1}=2.71[\mathrm{~Hz}]$; (b) $\mathrm{f}_{2}=5.19[\mathrm{~Hz}]$; (c) $\mathrm{f}_{3}=6.32[\mathrm{~Hz}]$. 


\section{Assessment of human-induced vibrations}

The risk of resonance phenomenon affected by dynamic loading generated by pedestrians was discussed taking into consideration the evaluated values of natural frequency. The frequency ranges of dynamic loading produced by walking and running pedestrians [9] are presented in Table 2 .

Table 2. Typical pacing frequencies for walking and running [9]

\begin{tabular}{|c|c|c|c|c|}
\hline \multirow{2}{*}{ Type of motion } & \multicolumn{4}{|c|}{ The range of frequencies [Hz] } \\
\cline { 2 - 5 } & Total & Slow & Normal & Fast \\
\hline walking & $1.4-2.4$ & $1.4-1.7$ & $1.7-2.2$ & $2.2-2.4$ \\
\hline running & $1.9-3.3$ & $1.9-2.2$ & $2.2-2.7$ & $2.7-3.3$ \\
\hline
\end{tabular}

For the pedestrian bridges the most common loading is generated by walking pedestrians. Loading generated by runners could also occur but this type of impact is less common on footbridges situated above highways and railways. The classification of the risk of resonance phenomenon for the footbridges is provided by the SÉTRA document [10]. The frequency ranges in the vertical and horizontal directions with the level of risk of resonance provided by the SÉTRA document [10] are presented in Table 3.

Table 3. The ranges of risk of resonance (SÉTRA) [10]

\begin{tabular}{|c|c|c|}
\hline \multirow{2}{*}{ Risk of resonance } & \multicolumn{2}{|c|}{ Frequency ranges $[\mathrm{Hz}]$} \\
\cline { 2 - 3 } & Vertical & Horizontal \\
\hline maximum & $1.7-2.1$ & $0.5-1.1$ \\
\hline medium & $1.0-1.7 ; 2.1-2.6$ & $0.3-0.5 ; 1.1-1.3$ \\
\hline low & $2.6-5.0$ & $1.3-2.5$ \\
\hline negligible & $0-1.0 ;>5.0$ & $0-0.3 ;>5.0$ \\
\hline
\end{tabular}

The investigation of the dynamic response to forces produced by a running person was conducted since the obtained first natural frequency $(2.76 \mathrm{~Hz})$ is in the typical range for running (1.9-3.3 Hz). However, it must be pointed out that, the risk of resonance is on the low level according to [10]. The forces caused by runners or walkers are periodic and change in time as well as space [11]. There are several proposals of mathematical interpretations of these types of loading in the literature. Despite the physical similarities, there are some differences between walking and running, i.e. the loading generated by a running user has a discontinuous nature [12]. Furthermore, the dynamic forces generated by runners can achieve a value of 2.0-2.5 times greater than value of body weight of pedestrian. In this research, loading generated by a runner was applied by a 'half-sine' model [13]. The 'half-sine' model is expressed by Eq. (1) and is dedicated only for loading generated by the runners:

$$
F(t)=\left\{\begin{array}{ccc}
A_{r} G_{0} \sin \left(\frac{\pi f_{r}}{k} t\right) & \text { for } & i \cdot T_{r}<t \leq(i+k) T_{r} \\
0 & \text { for } & (i+k) \cdot T_{r}<t \leq(i+1) T_{r}
\end{array}\right.
$$

where: $k$ - contact time factor $\left(k=t_{c r} / T_{r}\right) ; A_{r}$ - dynamic impact factor $\left(A_{r}=\pi /(2 \cdot k)\right)$; $t_{c r}-$ period of contact of the food with the ground; $T_{r}-$ period of running $\left(T_{r}=1 / f_{r}\right)$; $t$ - time. For adopted model, the parameters were selected on the basis of [13]. The values assumed in the study for the 'half-sine' model are summarised in Table 4. 
Table 4. The values of parameters for the 'half-sine' model [13]

\begin{tabular}{|c|c|c|c|c|c|}
\hline $\mathbf{f}_{\mathbf{r}}[\mathbf{H z}]$ & $\mathbf{T r}[\mathbf{s}]$ & $\mathbf{t}_{\text {cr }}[\mathbf{s}]$ & $\mathbf{G}_{\mathbf{0}}[\mathbf{N}]$ & $\mathbf{k}[-]$ & $\mathbf{A}_{\mathbf{r}}[-]$ \\
\hline 2.71 & 0.37 & 0.19 & 700 & 0.51 & 3 \\
\hline
\end{tabular}

The dynamic performance of the footbridge to loading generated by runner was performed using full-time history analysis. It was conducted with the Hilber-Hughes-Taylor time integration algorithm provided in the ABAQUS/Standard software for a direct step-bystep solution. The step varied from $10^{-5}$ to $10^{-2} \mathrm{~s}$. The Rayleigh model of damping was used for the numerical simulations. The coefficients of this damping model were calculated on the basis of experimental results for the first and the second mode shape (see Tab. 1 and Fig. 3). The mass proportional damping coefficient was equal to $\alpha=0.379$ and stiffness proportional damping coefficient was equal to $\beta=0.00022$, respectively. The maximum values of the accelerations which were obtained for the all control points (see Fig. 1) are summarized in Table 5. In Fig. 4, the time history of accelerations for A3 control point are presented. It is clearly visible (see Tab. 5), that the difference between the results which were obtained due to in situ tests and FE analysis did not exceed $15 \%$.

Table 5. The comparison of results for one pedestrian running scenario

\begin{tabular}{|c|c|c|c|}
\hline \multirow{2}{*}{ Control point } & \multicolumn{2}{|c|}{ Acceleration [m/ $\left.\mathbf{s}^{\mathbf{2}}\right]$} & \multirow{2}{*}{$\begin{array}{c}\text { Difference } \\
{[\%]}\end{array}$} \\
\cline { 2 - 3 } & In situ & FE model & $14 \%$ \\
\hline A1 & 0.27 & 0.30 & $10 \%$ \\
\hline A2 & 0.40 & 0.44 & $13 \%$ \\
\hline A3 & 0.56 & 0.63 & $12 \%$ \\
\hline A4 & 0.51 & 0.57 & \\
\hline
\end{tabular}
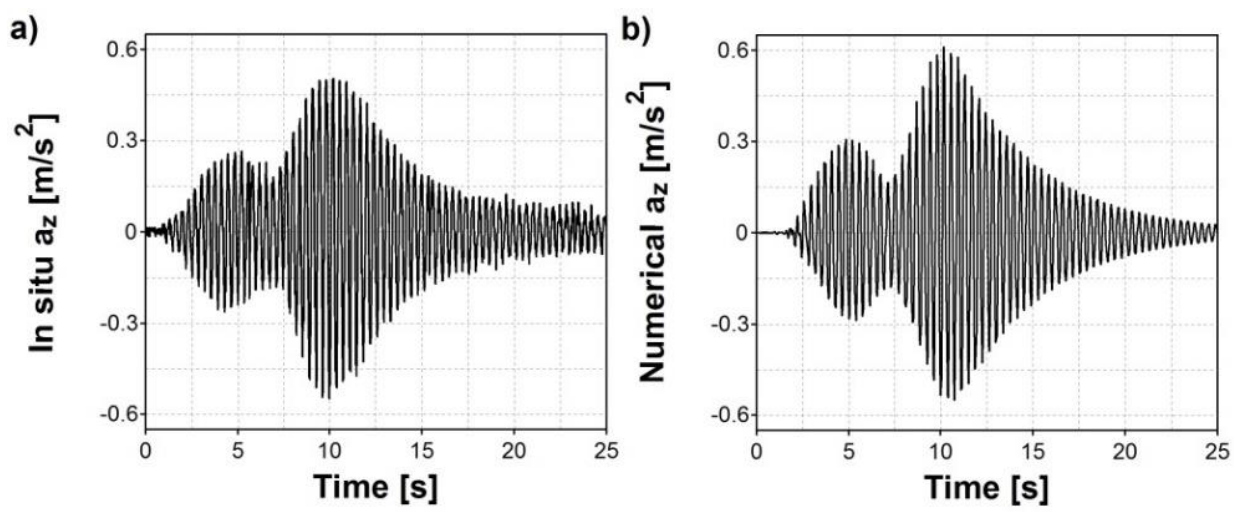

Fig. 2. The time history of accelerations in A3 control point: (a) in situ test and (b) numerical analysis.

The comfort criteria assessment was the last stage of the investigation and was based on EC rules [14] and the SÉTRA document [10]. The acceptable level of accelerations provided by EC is equal to $0.7 \mathrm{~m} / \mathrm{s}^{2}$ for vertical direction [14]. The SÉTRA document classifies footbridges on the basis of the traffic level and maximum values of accelerations, i.e. structures in an urban area are not analysed in the same way as pedestrian bridges in the open country. For discussed footbridge, the vertical comfort criteria were exceeded according to EC criteria. According to rules provided by the SÉTRA [10], the vertical vibration comfort level of the structure was categorised as 'mean'. 


\section{Conclusions}

The main aim of the presented study was the assessment of human-induced vibrations of the cable-stayed footbridge. The numerical as well as experimental procedures were conducted. From the investigation, the following main remarks can be provided:

- The risk of a resonance phenomenon caused by human generated loading occurred in the case of investigated structure. The lowest calculated vertical natural frequency was equal to $2.71 \mathrm{~Hz}$ and it coincides with the frequency of human steps while running;

- For the investigated footbridge, the comfort criteria were passed according EC [12] and SÉTRA document. However, according to rules provided by the SÉTRA [10], the vertical vibration comfort level of the structure was categorised as 'mean';

- Referring to final results of the study (see Tab. 4 and Fig. 2), it is clearly visible that the numerical simulations with the 'half-sine' model of dynamic forces generated by running pedestrian are efficient and practical tools.

\section{References}

[1] O. Oviedo-Trespalacios, B. Scott-Parker, Transport Res F-Traf 49,177-87 (2017)

[2] H. Bachmann, Proc of Footbridge 2002 (2002)

[3] A. Flaga, Warsaw: WKŁ (2011)

[4] E. Caetano, A. Cunha, Proc of ICSA 2013 (2013).

[5] I.J. Drygala, J.M. Dulinska, Procedia Engineer 199, 2937-42 (2017)

[6] I.J. Drygala, J.M. Dulinska, W. Wazowski, Procedia Engineer 193, 525-32 (2017)

[7] ABAQUS Users' Manual v. 6.13. Dassault Systemes Simulia Corp., Providence, RI. (2013)

[8] D.J. Ewins, Research Studies Press Ltd., Philadelphia (2000)

[9] S. Zivanovic, A. Pavic, P. Reynolds, J Sound Vib 279, 1-74 (2005)

[10] SÉTRA 2006: Assessment of vibrational behaviour of footbridges under pedestrian loading. Technical guide. Technical Department for Transport, Roads and Bridges Engineering and Road Safety, Paris, France (2006)

[11] H. Bachmann, W. Ammann, Zürich: IABSE - AIPC - IVBH (1987)

[12] A. Occhiuzzi, M. Spizzuoco, F. Ricciardelli, Struct Control Hlth 15, 349-68 (2008)

[13] M. Pańtak, MATEC Web of Conferences, $64^{\text {th }}$ Scientific Conference Krynica-Zdroj 2018, September 16 - 20, 2018, Poland (2018, to be published)

[14]EN 1990:2002/Al Eurocode - Basis of structural design, CEN, Brussels (2005) 